\title{
Occupational Accidents Among Elderly Farmers in Sweden
}

\author{
Kerstin Nilsson ${ }^{\mathrm{a}, \mathrm{b},{ }^{*}}$ and Stefan Pinzke ${ }^{\mathrm{a}}$ \\ ${ }^{a}$ Department of Work Science, Business Economics and Environmental Psychology, Swedish University of \\ Agricultural Sciences, PO Box 88 SE-230 53 Alnarp, Sweden. \\ ${ }^{b}$ Department of Occupational and Environmental Medicine, Lund university, SE-221 85 Lund, Sweden.
}

\begin{abstract}
The workforce in many countries nowadays is becoming older due to demographic change. Compared with many other occupations, farmers often work until a higher age. This study analysed occupational accidents to farmers in Sweden from an age perspective using data on 223 work injuries on farms and 990 road accidents involving tractors. The results showed that older farmers were not significantly more often injured than younger farmers, but appeared to suffer more hits and kicks from animals and were involved in more vehicle accidents than younger farmers. Older tractor drivers were more often involved in road turning accidents and in overtaking accidents involving private cars. Older farmers also sustained more skeletal injuries and took longer to heal after an accident.
\end{abstract}

Keywords: Elderly farmer, occupational accidents, older worker

\section{Introduction}

The demographic change occurring in many countries nowadays means that the workforce is becoming older. In the EU25, it is estimated that more than $33 \%$ of men and $38 \%$ of women in the population will be 60 years or above by 2050, up from $18 \%$ of men and $24 \%$ of women in 2000 [1]. Farmers are one of the occupational groups that often work until they are beyond the normal retirement age in Sweden. At the same time, the agricultural sector is the most hazardous work environment in Sweden. Of those working in agriculture in Sweden, $22 \%$ are currently aged $55-64$ years and $15 \%$ are 65 years or older [2]. Work-related accidents and deaths cause economic losses to organisations and society but, even more importantly, physical and mental suffering to individuals and families. Research shows that it is mainly the elderly who run the risk of accidents [3; 4]. For example, the number of reported work-related injuries resulting in 14 or more days of absence from work increases with age [5]. In 2007, 75 persons died in Swedish workrelated accidents [5]. Of these, $33 \%$ were 55 years old or more, although only $22 \%$ of the workforce was in this age group [5]. Most of the accidents and deaths among the workforce in Sweden occur in agriculture and forestry [5]. Of the total of 727 people in Sweden who died from work-related accidents in the period $1997-2007,7 \%$ of the individuals and $72 \%$ of the sites fell within the sector of agriculture and forestry [5].

This study examined whether elderly farmers and agricultural workers in Sweden tend to be more involved in work-related accidents and whether some types of accidents happen more often in the oldest age group.

\footnotetext{
* Corresponding author: Kerstin Nilsson, University teacher, PhD student, Department of Work Science, Business Economics and Environmental Psychology, Swedish University of Agricultural Sciences, PO. Box 88, SE-230 53 Alnarp, Sweden. Phone: +46 40 415497; E-mail: kerstin.nilsson@slu.se, Department of Occupational and Environmental Medicine, Lund university, SE-221 85 Lund, Sweden. Phone: +46 70 25629 80, E-mail: kerstin.nilsson@med.lu.se.

$1051-9815 / 12 / \$ 27.50$ @ 2012 - IOS Press and the authors. All rights reserved
} 


\section{Materials and Methods}

The data used in the study was obtained through telephone interviews with 223 injured farmers $(96 \%$ men and $4 \%$ women) performed by the Swedish University of Agriculture Science in collaboration with Statistics Sweden.

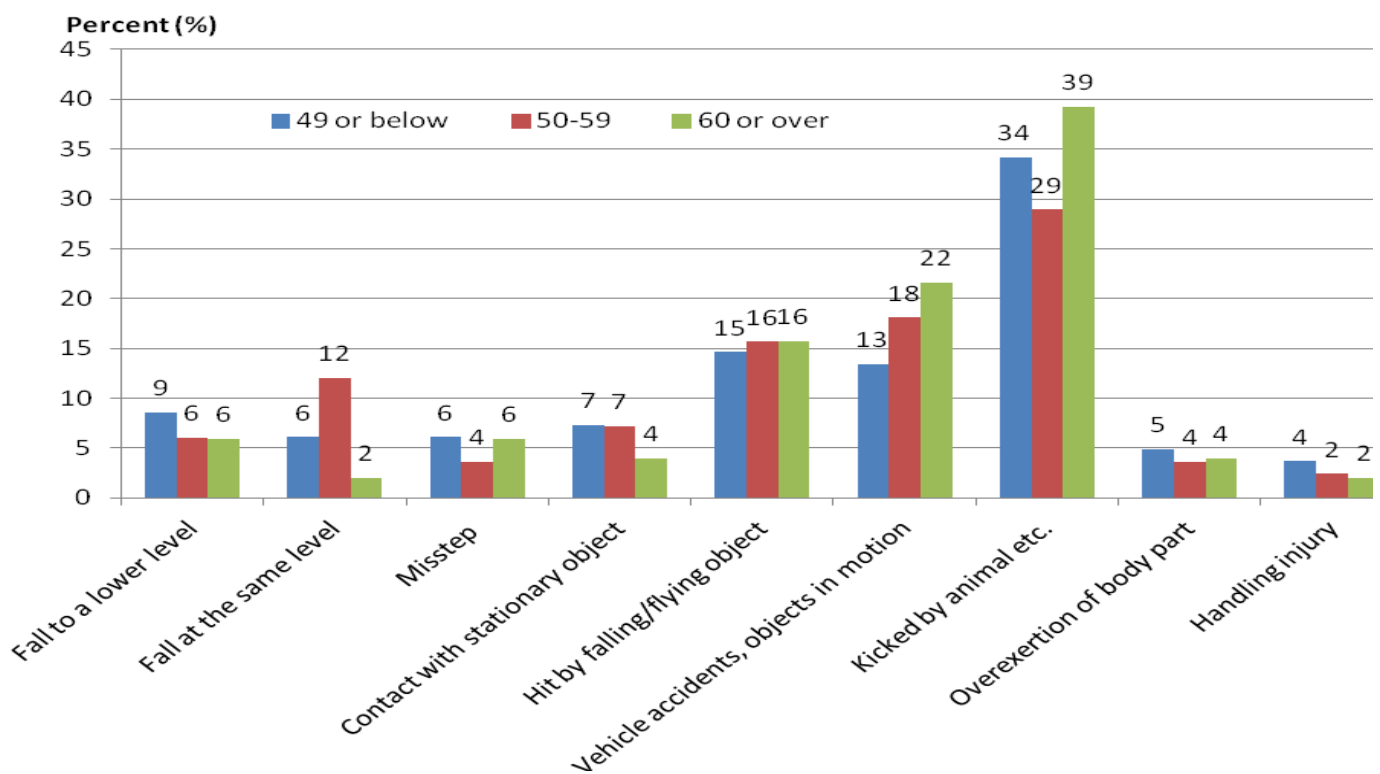

Figure 1

Percentage of work-related accidents to Swedish farmers, classified according to age group.

\section{Results}

In this study 6 percent of the agricultural holders have suffer of work related accidents during one year. The injury frequency between the age groups was 4 percent in age 49 or below, 5 percent in age $50-59$ and 4 percent in age 60 or over. 78 percent of the holders had been severely injured to the point where they had to seek medical help. In an age perspective 81 percent of the respondents were 60 year and over, 71 percent were $50-59$ year and 85 percent 49 years old or below who, due to the accident, had to seek medical help ( $p=0,00$; CI. 1,01-1,35). Older farmers incurred more hits and kicks by animals and more vehicle accidents than younger farmers (figure 1). Older farmers were more often injured outdoors and sustained more skeletal injuries, particularly ankle and foot injuries (figure 2). Of the injured 65 percent of the ones in age group 49 years or below, 70 percent of age 50-59 and 70 percent of age 60 or above did not use the Swedish social health insurance $(p=0,00$; CI. $1,65-2,10)$. Of the ones in the oldest age group 17 percent were not allowed to use the social health insurance because of age restrictions in the system. 


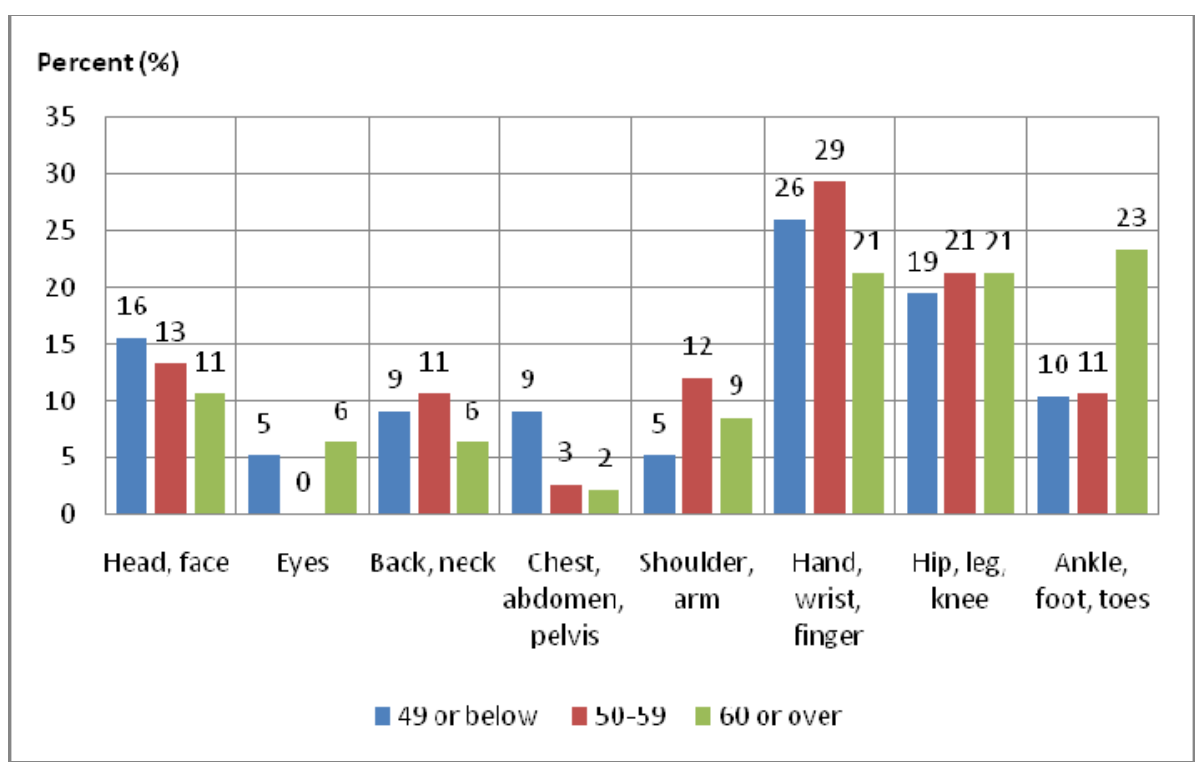

Figure 2

Percentage of work-related injuries to different parts of the body of Swedish farmers, classified according to age group.

\section{Discussion}

It is necessary to be careful and consider risks in all age groups, but elderly farmers in particular need to bear in mind that their bodies are no longer as young and strong as before. Their sense of distance vision, hearing and reactions may be decreasing, increasing the risk of accidents. Older farmers also took longer to heal after an accident Due to the longer healing process, slower reactions, ageing bodies and failing senses, elderly workers probably need to be even more careful and think over their work situation, driving and work environment to avoid accidents during the final years of their working life.

\section{Acknowledgements}

This study was financially supported by grants from the SLO fund. We are also indebted to Statistics Sweden for supplying the accident data.

\section{References}

[1] OECD. Population pyramids in 2000 and 2050. OECD Statistics Portal: Demography and Population; 2007. http://www.oecd.org/dataoecd/52/31/38123085.xls (2011 02 28)

[2] The Swedish Board of Agriculture 2006 The Employed in Agriculture 2005. JO 30 SM 0601. Statistics Sweden. Available at http://jordbruksverket.se/webdav/files/SJV/Amneso mraden/Statistik,\%20fakta/Sysselsattning/JO30/JO30SM060 1/JO30SM0601_ikortadrag.htm Accessed 10 (2011 02 28). (In Swedish)

[3] Danielsson K. 2000 Who has been injured at home? And how? EHLASS 2000:26. The Swedish Consumer Agency, Stockholm. (In Swedish)

[4] SRSA - Swedish Rescue Service Agency 2007 Accidents in numbers. The change of accidents in Sweden 2007. Swedish Rescue Service Agency, Karlskoga. (In Swedish)

[5] The Swedish Board of Agriculture 2008 Agricultural Statistics 2008. Statistics Sweden, Stockholm. (In Swedish) 